\title{
Impact of Urbanization on Stormwater Runoff from a Small Urban Catchment: Gdańsk Małomiejska Basin Case Study
}

\author{
Borys Olechnowicz, Katarzyna Weinerowska-Bords \\ Gdańsk University of Technology, Faculty of Civil and Environmental Engineering, Department of \\ Hydraulic Engineering, ul. G. Narutowicza 11/12, 80-233 Gdańsk, Poland, e-mail: kwein@pg.gda.pl
}

(Received June 09, 2014; revised December 08, 2014)

\begin{abstract}
This paper deals with the impact of different forms of urbanization on the basin outflow. The influence of changes in land cover/use, drainage system development, reservoirs, and alternative ways of stormwater management (green roofs, permeable pavements) on basin runoff was presented in the case of a small urban basin in Gdańsk (Poland). Seven variants of area development (in the period of 2000-2012) - three historical and four hypothetical - were analyzed. In each case, runoff calculations for three rainfall scenarios were carried out by means of the Hydrologic Modeling System designed by Hydrologic Engineering Center of the U.S. Army Corps of Engineers (HEC-HMS). The Soil Conservation Service (SCS) Curve Number (CN) method was used for calculations of effective rainfall, the kinematic wave model for those of overland flow, and the Muskingum-Cunge model for those of channel routing. The calculations indicated that urban development had resulted in increased peak discharge and runoff volume and in decreased peak time. On the other hand, a significant reduction in peak values was observed for a relatively small decrease in the normal storage level (NSL) in reservoirs or when green roofs on commercial centers were present. The study confirmed a significant increase in runoff as a result of urbanization and a considerable runoff reduction by simple alternative ways of stormwater management.
\end{abstract}

Key words: urban development, basin runoff, numerical modeling, green roofs, permeable pavement

\section{List of Symbols}
$A$ - cross-section area,
$B \quad-$ surface width of the channel,
$c \quad-$ flood wave speed,
$C N$ - Curve Number in SCS methods (parameter),
$\mathrm{Cr}$ - Courant number,
$D$ - collector diameter,
$F_{a}$ - cumulative infiltration,
$g$ - acceleration due to gravity, 
$I$ - inflow into the channel section,

$I_{a} \quad$ - initial rainfall losses (abstractions),

$K$ - parameter in Muskingum models,

$L$ - length of the channel/conduit (or channel/conduit section),

$m$ - empirical parameter,

$m_{1}$ - parameter in the kinematic wave model,

$n_{o}$ - overland resistance coefficient,

$O$ - outflow from the channel section,

$P \quad-$ cumulative total rainfall,

$P_{e}-$ cumulative effective rainfall,

$Q$ - discharge,

$q$ - lateral inflow per unit length of the channel,

$Q_{o}$ - reference discharge,

$Q_{p}$ - peak discharge,

$S$ - potential maximum retention of the basin,

$S_{f}-$ energy gradient (hydraulic slope),

$S_{o}$ - bottom slope,

$T_{p}$ - time of peak discharge occurrence,

$V \quad-$ storage of the channel section; volume of water,

$v$ - average cross-section velocity,

$X$ - parameter in Muskingum models,

$y \quad-$ hydraulic depth,

$\alpha-$ parameter in the kinematic wave model,

$\Delta t$ - time step,

$\Delta x-$ spatial step.

\section{Introduction}

The accurate determination of the amount of water involved in basin outflow requires proper recognition of the course and intensity of the rainfall-runoff transformation in the basin under analysis. The nature of this transformation is a result of many interdependent processes constituting the water cycle and determining water balance in the given location. Each of these processes suffers from relatively high complexity, so the accurate mathematical description of the relations analyzed is not only very difficult, but - in an all-embracing and exhaustive form - impossible (McCuen 2005). Moreover, the phenomena that can be recognized in a natural environment are additionally modified in a significant way by the urbanization of the basin. Development of the basin areas not only influences the catchment itself, but also significantly changes the course and proportions of the processes constituting water balance. The most important features that distinguish urban basins from other catchments and determine the above changes are their relatively small size and modified boundaries (usually enforced by a human-designed drainage system and modified land slopes), a large 
proportion of developed (impervious) areas and a small proportion of vegetation, relatively low overland roughness, and the presence of an artificial system of channels and collectors (Chow 1964, McCuen 2005). As a consequence, the processes of interception, evapotranspiration, infiltration, and natural surface retention are reduced, so that the amount of water produced by runoff is much higher. Besides, the rainfall-runoff transformation proceeds with greater speed and intensity, as the lag time and concentration time for the basin decrease, and the flood wave peak increases. What is more, characteristic temperature and humidity conditions in urban areas, especially in highly developed agglomerations, may lead to the effect of heat island, which constitutes a local microclimate, usually different from conditions outside the agglomeration. In the long term, it influences precipitation, leading to a higher frequency of extreme storm events (Walesh 1989, Lutgens and Tarbuck 2004). This additionally modifies the rainfall-runoff transformation in such areas.

The assessment of the impact of urbanization on different aspects of broadly defined environmental engineering is an important problem. Such an assessment may include both the reconstruction of former changes in an urban environment and the forecasting of future threats and needs. It is particularly useful as a decision-supporting tool in town development. It may help not only to design and control drainage systems, or to assess the flood risk and provide necessary protection (e.g. reservoir design and control), but also to analyze the potential sensitivity of outflow to alternative ways of rainfall water collection and management, such as porous pavements (e.g. in parking lots, playing yards, communications routes etc.), green roofs, detention ponds, infiltration basins, etc.

The best of the available techniques for determining the impact of urbanization is a long-term monitoring of rainfall and runoff in a basin that has been gradually urbanized. However, catchments for which such measurements are available are very rare, making this method impracticable in most typical cases (Walesh 1989). The second approach consists in the observation of runoff in two basins, similar in basic hydrological characteristics except urban development. This method, however, may also be difficult in practice. Another, often applied, approach is therefore to apply mathematical modeling, combined with empirical or theoretical tools for parameter identification.

Up till now, a very wide range of models of the rainfall-runoff transformation have been developed: from very simple ones (e.g. based on the rational method and its modification), in which all complicated relations describing this transformation are reduced to one governing equation of very simple structure, through different types of conceptual models, to complex integrated models, in which each of the processes is considered individually (Chow 1964, Walesh 1989, Campana and Tucci 2001, Akan and Houghtalen 2003, Wissmar et al 2004, Vicars-Groening and Williams 2007, Shi et al 2007, Sangjun et al 2009; and others). It is obvious that a more complex model should ensure a better agreement between modeled and real processes, and thus it should lead to better results. However, in practice, what frequently determines the 
choice of the model is data availability. The majority of urban basins are uncontrolled, which means that there are no continuous and reliable measurements, necessary for proper calibration and validation of a model. In such cases, it is extremely important to choose a model in which as many parameters as possible are physically based and therefore directly measurable or easily determined on the basis of different types of basin characteristics. Parameters of empirical nature are very difficult to verify in such a case and should be avoided.

This paper presents selected aspects of basin changes due to urbanization, possible rainfall water management strategies, their influence on runoff, and their mathematical modeling in the case of a developed area in a Polish city of Gdańsk.

\section{Study Case Description}

The study presents an analysis of the Małomiejska basin, located in the southern part of the city of Gdańsk (Poland) (Fig. 1, Fig. 2). It is an urban area that has undergone a rapid and intensive development over the last decade. The proportion of residential and commercial areas increased significantly, causing a decrease in undeveloped and forested areas, as well as a considerable increase in the amount and intensity of runoff. The nearest future is likely to be a period of further dynamic development of the area, so further increase in runoff is expected. Since the area is located in the upper part of the city, runoff characteristics have a significant influence not only on local conditions, but also on the situation in lower parts of the city (close to the Gulf of Gdańsk, Fig. 1). Past events, especially the catastrophic flood in Gdańsk in 2001, prove that this aspect is very important (Wołoszyn 2003).

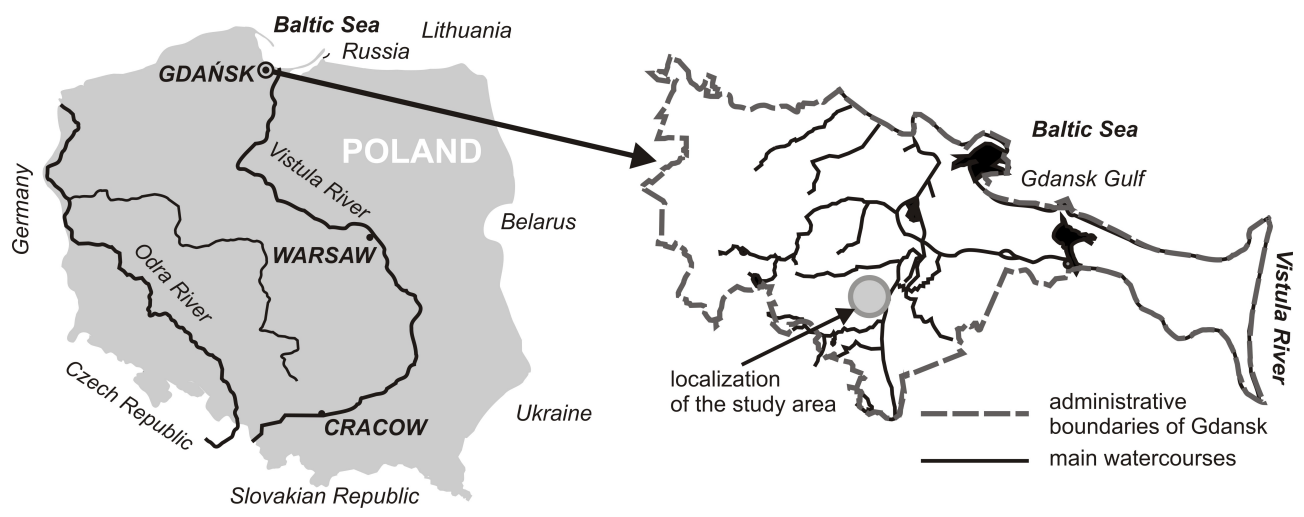

Fig. 1. Localization of the study case area

The drainage basin under discussion has an area of 370 ha and boundary length of $11.28 \mathrm{~km}$. The elevations of the highest and the lowest points in the basin are $99 \mathrm{~m} 9 \mathrm{~m}$ above mean sea level (MSL). The average slope of the basin is $4.68 \%$. The existing system of collectors transporting stormwater to the outlet consists of the 


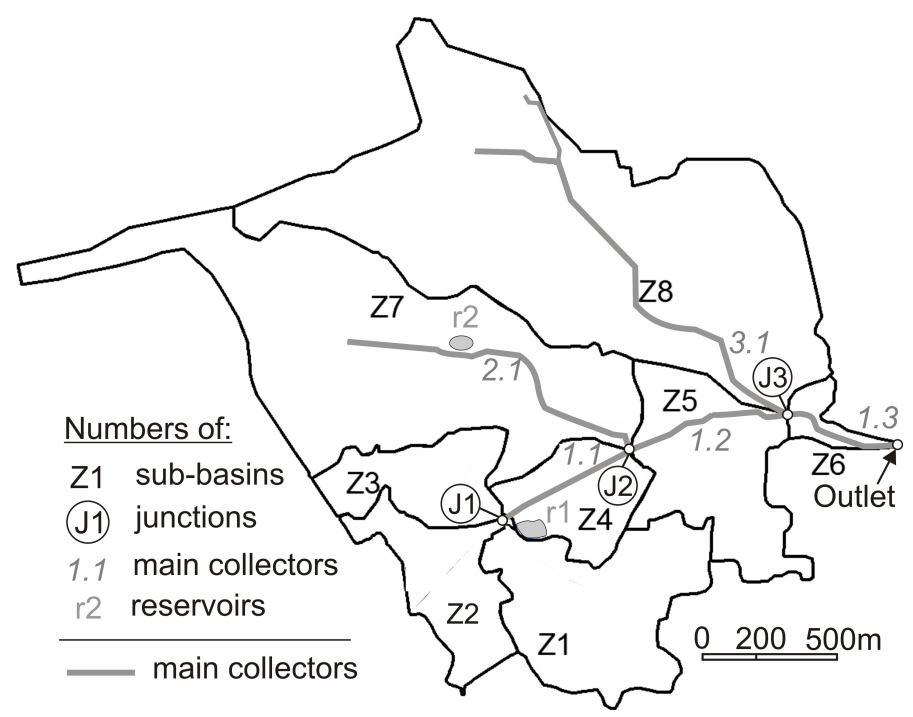

Fig. 2. General shape and main components of the basin Małomiejska

main collector and lateral conduits. The shape of the basin and the general routes of the main collectors are presented in Fig. 2. The biggest collector is situated along the Małomiejska street (hence the name of the basin) and is constituted by three main sections: 1.1 (diameter $D=0.6 \mathrm{~m}$, length $L=0.543 \mathrm{~km}), 1.2(D=1.4 \mathrm{~m}, L=0.626$ $\mathrm{km})$ and $1.3(D=1.4 \mathrm{~m}, L=0.465 \mathrm{~km})$. The lateral collectors are $2.1(D=0.8 \mathrm{~m}$, $L=1.243 \mathrm{~km})$ and $3.1(D=1.0 \mathrm{~m}, L=1.387 \mathrm{~km})$.

In the study, different levels of basin development are analyzed and compared: "past" (situation in 2000), "present" (situation in 2011) and "alternative" (modified case of 2011, with three variants of hypothetical development). The characteristics of the basin in 2000 and in 2011 have been determined on the basis of ortophotomaps, topographic maps, aerial pictures (taken in 2011), maps of water infrastructure, map of soils, and other available documentation, and have been complemented by local inspection. The description of the location and its natural environment (with respect to the geographical regionalization of the country) has been complemented by earlier studies of the area.

The distributions of different types of land use and land cover in 2000 and in 2011 are presented in Fig. 3 and Fig. 4, respectively. A comparison of the proportion of different categories of land use/cover in 2000 and 2011 is shown in Fig. 5. The distribution of different types of soils at a depth of $1 \mathrm{~m}$ below the terrain level and the location of additional embankments in the basin are presented in Fig. 6.

For computational purposes, the area of the Małomiejska basin was divided into eight sub-basins Z1-Z8 (Fig. 2). For each of the sub-basins, catchment characteristics (for 2000 and 2011) concerning geometry, landform, land use, and the proportion of 


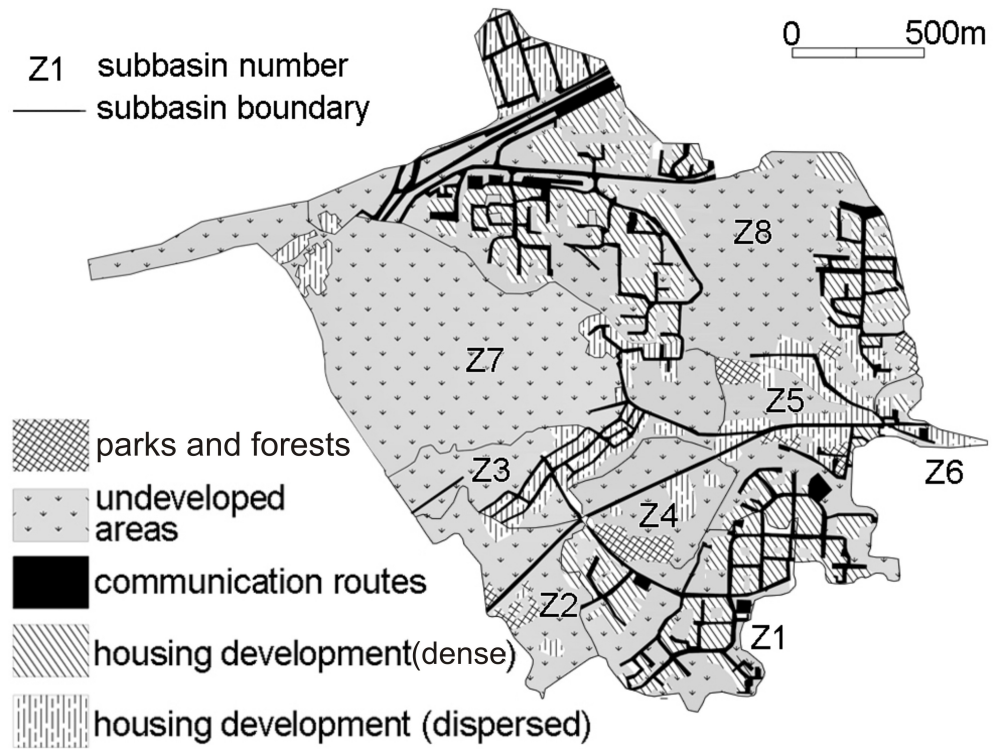

Fig. 3. Land-use and land-cover of the study basin area in 2000 (Olechnowicz 2012)

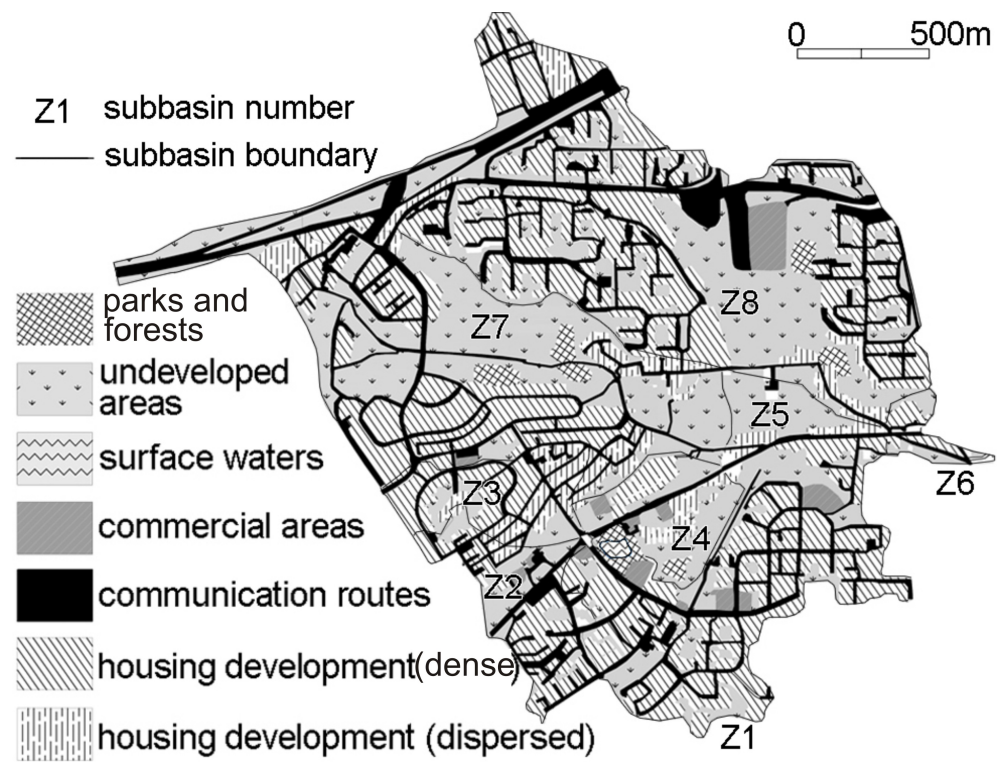

Fig. 4. Land-use and land-cover of the study basin area in 2011 (Olechnowicz 2012)

different types of soils were determined on the basis of maps and photos. Selected values of the calculated characteristics are presented in Table 1.

As can be seen, the land use/cover in 2000 and 2011 differs considerably. Moreover, in 2000 stormwater retention in the basin was not supported by any reservoirs. Nowadays, two reservoirs are used. The location of the first, the Platynowa reservoir 


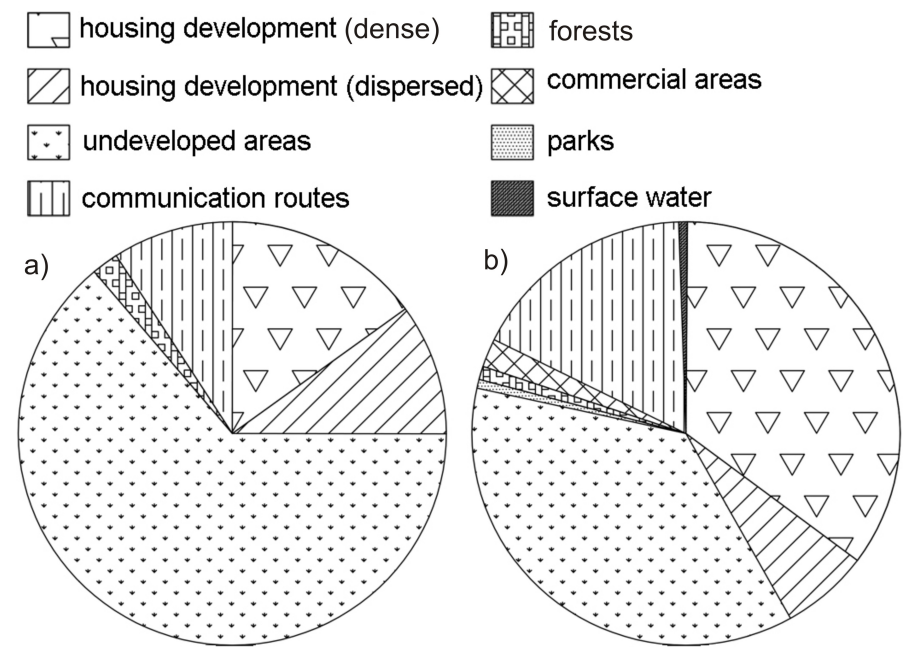

Fig. 5. Comparison of land-use and land-cover of study basin: a) in 2000, b) in 2011 (Olechnowicz 2012)

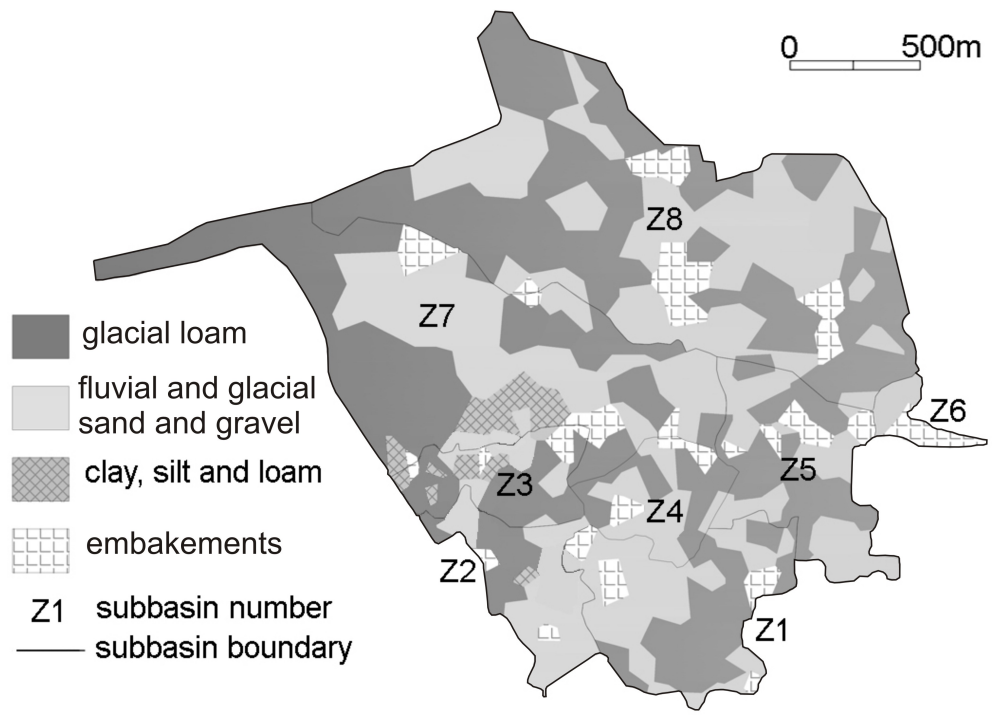

Fig. 6. Soil distribution (1 m below terrain level) (Olechnowicz 2012)

(in operation since 2002) is presented in Fig. 2 (r1) and Fig. 4. The total flood control storage of this reservoir is $33230 \mathrm{~m}^{3}$. Its normal storage level (NSL) and maximum storage level are $38.32 \mathrm{~m}$ and $38.82 \mathrm{~m}$ above MSL, respectively. The reservoir surface area for NSL is $0.63 \mathrm{ha}$. The side slope is $1: 2$. Stormwater collected from sub-basins $\mathrm{Z} 1$ and $\mathrm{Z} 2$ is introduced into the reservoir by two circular inflow conduits of diameter $0.8 \mathrm{~m}$. The outflow from the reservoir is provided by a collector of $D=0.3 \mathrm{~m}$, which leads water to collector 1.1. 
Table 1. Main characteristics of sub-basins constituting Małomiejska basin

\begin{tabular}{|c|c|c|c|c|c|c|c|c|c|c|c|c|c|c|}
\hline \multirow{3}{*}{$\begin{array}{l}\text { Sub- } \\
\text { basin }\end{array}$} & \multirow{3}{*}{$\begin{array}{l}\text { Area } \\
{\left[\mathrm{km}^{2}\right]}\end{array}$} & \multirow{3}{*}{$\begin{array}{c}\text { Average } \\
\text { land slope } \\
{[\%]}\end{array}$} & \multicolumn{12}{|c|}{ Area of land-use category $C_{i}$ [ha] } \\
\hline & & & \multicolumn{5}{|c|}{2000} & \multicolumn{7}{|c|}{2011} \\
\hline & & & $C_{1}$ & $C_{2}$ & $C_{3}$ & $C_{4}$ & $C_{5}$ & $C_{1}$ & $C_{2}$ & $C_{3}$ & $C_{4}$ & $C_{5}$ & $C_{6}$ & $C_{7}$ \\
\hline $\mathrm{Z1}$ & 0.38 & 4.53 & 14.54 & 0.00 & 16.22 & 1.36 & 6.08 & 21.56 & 0.00 & 7.49 & 0.44 & 6.83 & 1.88 & 0.00 \\
\hline $\mathrm{Z} 2$ & 0.20 & 0.99 & 0.29 & 1.24 & 16.65 & 1.27 & 0.55 & 8.33 & 0.61 & 5.74 & 0.00 & 4.82 & 0.47 & 0.00 \\
\hline $\mathrm{Z3}$ & 0.18 & 10.09 & 0.00 & 4.24 & 12.25 & 0.00 & 1.29 & 6.86 & 4.52 & 3.25 & 0.00 & 3.13 & 0.00 & 0.00 \\
\hline $\mathrm{Z} 4$ & 0.17 & 4.82 & 0.00 & 1.76 & 13.61 & 1.38 & 0.55 & 2.17 & 2.31 & 8.87 & 1.43 & 0.97 & 0.90 & 0.63 \\
\hline $\mathrm{Z5}$ & 0.33 & 7.01 & 7.48 & 5.33 & 13.68 & 2.17 & 4.03 & 12.20 & 2.10 & 13.10 & 0.00 & 4.04 & 1.12 & 0.00 \\
\hline Z6 & 0.05 & 7.00 & 0.53 & 1.44 & 1.96 & 0.00 & 0.62 & 1.95 & 0.09 & 1.89 & 0.05 & 0.62 & 0.00 & 0.00 \\
\hline $\mathrm{Z7}$ & 0.98 & 7.47 & 0.00 & 9.13 & 86.99 & 0.00 & 1.96 & 24.99 & 8.48 & 45.84 & 2.50 & 14.04 & 0.31 & 0.00 \\
\hline Z8 & 1.41 & 5.30 & 32.75 & 13.84 & 74.60 & 1.04 & 18.71 & 52.61 & 6.04 & 49.39 & 1.60 & 28.79 & 3.18 & 0.00 \\
\hline
\end{tabular}

The other reservoir (Madaliñskiego reservoir) has been in operation since November 2011, and therefore two variants of calculations - without (2011) and with (2012) this reservoir - were carried out. This reservoir, situated in the central part of sub-basin $\mathrm{Z7}$ (indicated as $\mathrm{r} 2$ in Fig. 2), has a total flood control storage of $32737 \mathrm{~m}^{3}$, NSL of $45.70 \mathrm{~m}$, maximum storage level of $46.90 \mathrm{~m}$, surface area for NSL of $0.53 \mathrm{ha}$, and side slope of $1: 3$. Its main purpose is to support stormwater retention in this part of the basin, which is characterized by very intensive development, also forecasted for the nearest future. Stormwater is introduced into the reservoir by a circular inflow conduit of diameter $0.8 \mathrm{~m}$. The outflow from the reservoir is provided by a weir with two orifices, from which stormwater flows into a chamber and is further drained by a circular collector of $D=0.8 \mathrm{~m}$. For computational reasons, because of the presence of the reservoir, sub-basin $\mathrm{Z7}$ is divided into its upper part Z7.1, from which stormwater flows to the upper section of collector 2.1 and to the reservoir, and its lower part $\mathrm{Z7.2}$, which supplies the lower section of the collector and junction $\mathrm{J} 2$.

Construction schemes and geometric data for both reservoirs were used to establish the elevation-outflow (discharge) and elevation-surface area relationships. An example of such functions for the Platynowa reservoir is presented in Fig. 7.

\section{Runoff Calculations}

\subsection{Basin Model}

In the study, several variants of basin characteristics, for different stages of drainage area development, were analyzed:

1. land use/cover in 2000, with no reservoirs;

2. land use/cover in 2011, with the Platynowa reservoir;

3. land use/cover in 2012, with both reservoirs;

4. land use/cover in 2011, with no reservoirs (hypothetical, for comparison). 


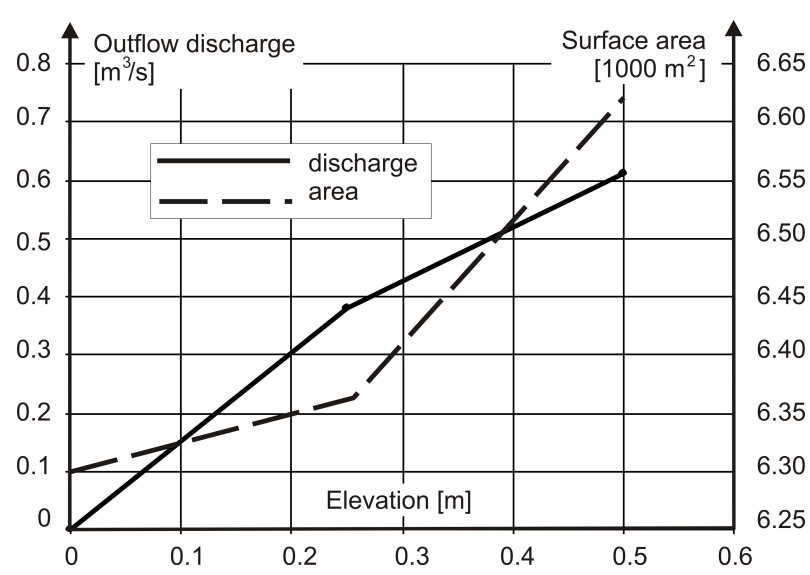

Fig. 7. Outflow discharge and surface area for Platynowa reservoir in function of elevation over NSL

In addition to the above variants, three further hypothetical cases, referring to alternative stormwater management in selected parts of the catchment, were analyzed:

5. land use/cover in 2011, with the Platynowa reservoir and green roofs on commercial centers;

6. land use/cover in 2011, with the Platynowa reservoir, green roofs on commercial centers, and permeable (porous) parking lots;

7. land use/cover in 2012, with both reservoirs and NSL decreased by $25 \mathrm{~cm}$.

In variants 5 and 6 , the influence of green roofs and permeable parking surfaces on outflow is analyzed. In the basin under discussion, commercial areas, occupied mainly by low-rise, large-area hypermarkets, are located mainly in sub-basins Z1, $\mathrm{Z5}$, and Z8, and take up no more than $2.2 \%$ of the total basin area (Table 1, Fig. 5 ). Nonetheless, it is interesting whether the influence of commercial areas on runoff would be noticeable if all roofs were designed as green ones. Another important and relatively cheap method for runoff reduction is to increase infiltration by designing large parking lots as porous, permeable surfaces. Variant 6 represents a hypothetical situation in which all big parking lots are porous.

An additional way of increasing the volume of rainfall water collected "near the source" and not introduced into the drainage system is to increase the storage volume of reservoirs. Both reservoirs in the basin under discussion have been designed to store water continuously, both during wet and dry periods, with a relatively high NSL. That is why the flood control storage volume of the reservoirs is relatively low. Variant 7 represents a hypothetical situation in which water elevation in both reservoirs is kept $25 \mathrm{~cm}$ lower than originally designed. For this variant, new elevation-discharge and elevation-area functions were developed.

For each of the cases considered in the study, appropriate models of the basin were created with the use of the HEC-HMS package. Schemes representing the distribution 
of basin components (sub-basins, reservoirs, conduits) were developed and geometric data related to each of the components were introduced. On the basis of earlier analyses, the proportion of impervious areas for each sub-basin was determined for each of the variants (var. 1-var. 7). Additional parameters referring to the models selected to describe processes governing the rainfall-runoff transformation were introduced.

\subsection{Rainfall-runoff Transformation Models}

Rainfall-runoff calculations, if not reduced to the simplest one-equation model, may be schematically expressed as in Fig. 8. The rainfall-runoff model is in fact a combination of a finite number of sub-models describing mathematically the processes determining basin runoff. The rainfall input introduced into the model in the form of a total rainfall hyetograph is at first transformed into effective rainfall by the so-called "rainfall model." This sub-model is responsible for determining which part of the total rainfall is "lost" in the processes of interception, evapotranspiration, surface retention, and infiltration (the so-called rainfall losses/abstractions). The rest creates surface runoff and thus constitutes effective rainfall (rainfall excess). The other sub-models represent the processes of surface flow transformation, reservoir flow routing, and channel flow routing.

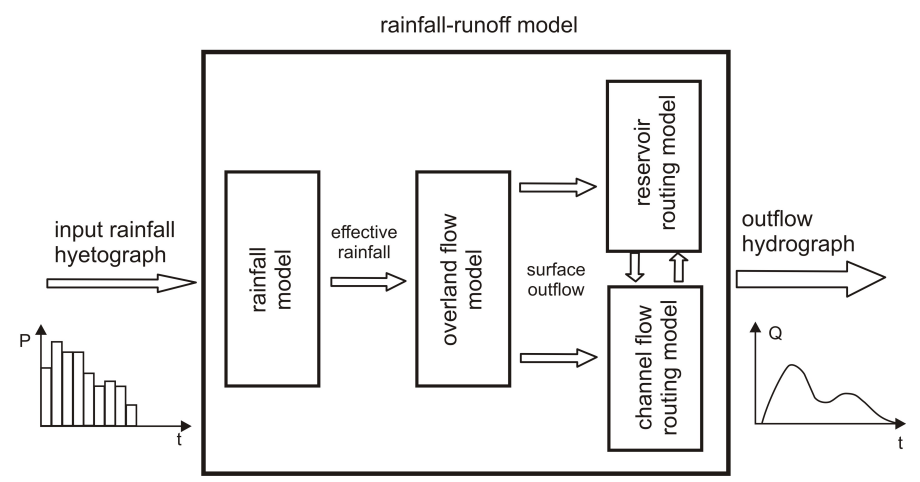

Fig. 8. Scheme of rainfall-runoff model

The HEC-HMS package, used in this study, is a widely known and often applied engineering tool for simulations of precipitation-runoff processes in a large variety of basins, including urban areas. HEC-HMS provides a wide range of models for each of the processes and is helpful in the analysis of many different hydrologic problems. Detailed information can be found in HEC-HMS manuals (Feldman 2000, Scharffenberg 2013).

The choice of the sub-models applied in the present study for each of the stages presented in Fig. 8 was determined by the characteristics of the catchment, quality and number of available data, and limited possibilities of parameter verification. 
For effective rainfall calculations, the Soil Conservation Service (SCS) Curve Number (CN) method was used (SCS 1986). The method estimates precipitation excess as a function of cumulative precipitation, soil cover, land use, and antecedent moisture. The method assumes that the ratio of cumulative infiltration $F_{a}$ to the potential maximum retention of the basin $S$ is equal to the ratio of cumulative effective rainfall $P_{e}$ to cumulative total rainfall $P$ decreased by the initial loss $I_{a}$ :

$$
\frac{F_{a}}{S}=\frac{P_{e}}{P-I_{a}} .
$$

Thus, taking into account the instantaneous water balance in the basin:

$$
P=I_{a}+F_{a}+P_{e}
$$

one eventually obtains:

$$
P_{e}(t)=\frac{\left(P(t)-I_{a}\right)^{2}}{P(t)-I_{a}+S}
$$

Until the accumulated rainfall exceeds the initial abstractions, the precipitation excess is equal to zero. On the basis of results from many experimental basins, the SCS suggests the empirical relation for initial losses as:

$$
I_{a}=m \cdot S,
$$

usually with $m$ equal to 0.2 (SCS 1986). Therefore, the cumulative excess at time $t$ is:

$$
P_{e}(t)=\frac{(P(t)-m \cdot S)^{2}}{P(t)+(1-m) \cdot S}
$$

The potential maximum retention of the basin $S$, which is a measure of the basin's capacity to abstract and retain storm precipitation, is related to basin characteristics through a parameter known as Curve Number $(\mathrm{CN})$, as:

$$
S=254\left(\frac{100}{C N}-1\right) \text {. }
$$

$\mathrm{CN}$ values are estimated on the basis of soil cover, land use, and antecedent moisture with the use of tables published by the SCS (SCS 1986). In the study, the composite values of $\mathrm{CN}$ were obtained by a detailed analysis of land cover/use and soil, the with assumption of normal initial soil moisture (Akan and Houghtalen 2003, Mays 2005).

For overland flow transformation, the well-known and widely applied kinematic wave model was used (Eagleson 1971, Mays 2005, Szymkiewicz 2010). The model represents the basin as a very wide open channel, with inflow into the "channel" equal to the effective rainfall. The runoff hydrograph is computed by solving a system of 
momentum and continuity equations constituting a mathematical description of unsteady shallow water flow. The first of the equations is obtained from the well-known Saint-Vennant dynamic equation (Chow 1964, Szymkiewicz 2010):

$$
\frac{\partial y}{\partial x}+\frac{v}{g} \frac{\partial v}{\partial x}+\frac{1}{g} \frac{\partial v}{\partial t}=S_{o}-S_{f}
$$

where $y$ is hydraulic depth, $v$ - average cross-section velocity, $g$ - acceleration due to gravity, $S_{o}$ - bottom slope, $S_{f}$ - energy gradient. After reducing pressure gradients and acceleration effects, which in the case of shallow flow are usually negligible (Chaundhry 1993), one obtains the final form of the dynamic equation in the kinematic flow model:

$$
S_{f}=S_{o}
$$

The energy gradient can be estimated from Manning's equation as:

$$
S_{f}=\frac{n_{o}^{2} v^{2}}{R^{4 / 3}},
$$

where $R$ is the hydraulic radius, and $n_{o}$ is an "overland" roughness coefficient (equivalent of the Manning roughness coefficient) depending on the cover of the planes (Akan and Houghtalen 2003). The Eq. 9 can be expressed as:

$$
S_{f}=\frac{n_{o}^{2} Q^{2}}{A^{2} R^{4 / 3}},
$$

where $Q$ is discharge, and $A$ is the cross-section area. Combining this with Eq. 8, one obtains a relation that may be further rewritten as:

$$
Q=\alpha A^{m_{1}},
$$

where $a$ and $m_{1}$ are parameters related to flow geometry and surface roughness.

The second equation in the system governing the 1D shallow flow is the continuity equation, which may be expressed as (Chow 1964, Feldman 2000, Szymkiewicz 2010):

$$
\frac{\partial Q}{\partial x}+\frac{\partial A}{\partial t}=q
$$

where $q$ is lateral inflow per unit length of the "channel." Combining Eq. 11 with Eq. 12 yields:

$$
\frac{\partial A}{\partial t}+\alpha m_{1} A^{m_{1}-1} \frac{\partial A}{\partial x}=q,
$$

which is a kinematic wave approximation of the equations of motion. For wide rectangular channels (appropriate for overland flow modelling), one obtains:

$$
\alpha=1.486 \frac{S_{0}^{1 / 2}}{n_{o}} \quad \text { and } \quad m_{1}=\frac{5}{3} .
$$


In order to solve Eq. (13), the partial differential equation is approximated with a finite-difference scheme proposed by Leclerc and Schaake (1973), which leads to system of algebraic equations solved at each time level:

$$
\begin{gathered}
\frac{A_{i}^{j}-A_{i}^{j-1}}{\Delta t}+\alpha m_{1}\left(\frac{A_{i}^{j-1}+A_{i-1}^{j-1}}{2}\right)^{m_{1}-1} \frac{A_{i}^{j-1}-A_{i-1}^{j-1}}{\Delta x}=\frac{q_{i}^{j}+q_{i}^{j-1}}{2} \\
\text { for } i=2, \ldots, N,
\end{gathered}
$$

where $i(i=1, \ldots, N)$ and $j(j=1, \ldots, M)$ are space and time indexes of the nodes in the space-time grid, while $\Delta x$ and $\Delta t$ are distance and time steps, respectively.

In the surface flow problem considered in this study, for $t=0$ no overland flow is observed, so the initial condition $(j=1)$ is defined by the cross-section area $A$ equal to zero. Additionally, no inflow at the upstream boundary of the overland-flow plane is imposed. The values of lateral inflow are determined on the basis of the known rainfall excess, with the assumption that it is constant within a time step and uniformly distributed along the element.

In order to ensure an accurate and stable solution, the numerical scheme implemented in HEC-HMS for the overland flow equation requires that the Courant number $\mathrm{Cr}$ be equal to unity:

$$
\mathrm{Cr}=c \cdot \frac{\Delta t}{\Delta x}=1
$$

where $c$ is the flood wave speed.

However, as the function of the flow depth $y$ (and hence the speed wave $c$ ) is variable in time and space, the condition expressed by Eq. 16 is very difficult to fulfill in practice. That is why a special procedure in HEC-HMS makes it possible to adjust the values of $\Delta t$ and $\Delta x$ automatically in order to meet stability and accuracy requirements under changing flow conditions (Feldman 2000).

In the present study, each of the sub-basins was represented by two planes (open-book model), for which geometric and roughness data were imposed separately. This approach makes it possible to distinguish impervious and pervious areas in each basin and to introduce different values of parameters for areas of different characteristics, instead of imposing one average value for the whole basin (Feldman 2000, Scharffenberg 2013). The kinematic wave model, selected for overland flow calculations, can be used for physically based analyses involving parameters with a clear physical interpretation. That eliminates the need to identify empirical parameters, which is impossible in the present case.

For channel flow routing, the Muskingum-Cunge model was applied (Cunge 1969, Mays 2005, Feldman 2000, Szymkiewicz 2010). In this approach, flow transformation along the channel is determined by solving the continuity equation, whose final form is obtained from the partial differential equation (Eq. 12) after its integration along 
the routing reach. As a result, one obtains a modified storage equation, known from reservoir models, including lateral inflow:

$$
\frac{d V}{d t}=Q_{i-1}(t)-Q_{i}(t)+q(t) \cdot \Delta x,
$$

where $V$ is the storage of the given channel section, whereas $Q_{i-1}$ and $Q_{i}$ are the functions of inflow and outflow discharges in the given reach (inflow and outflow hydrographs). In reservoir models, the behavior of the channel section is conceptually compared with the behavior of the reservoir, for which the relation between the storage $V$, inflow $Q_{i-1}$, and outflow $Q_{i}$ is known and described by the assumed formula, depending on the specific model. In the Muskingum model this relation is expressed as (e.g. Szymkiewicz 2010):

$$
V=K\left[X \cdot Q_{i-1}(t)+(1-X) \cdot Q_{i}(t)\right],
$$

where $K$ and $X(0 \leq X \leq 1)$ are empirical parameters, usually estimated by trial and error. Substituting Eq. 18 into Eq. 17, one obtains:

$$
X \frac{d Q_{i-1}}{d t}+(1-X) \frac{d Q_{i}}{d t}=\frac{1}{K}\left[Q_{i-1}(t)-Q_{i}(t)+q(t) \cdot \Delta x\right] .
$$

After approximation of Eq. 19 by the implicit trapezoidal scheme, the following system of equations is obtained:

$$
\begin{gathered}
X \frac{Q_{i-1}^{j}-Q_{i-1}^{j-1}}{\Delta t}+(1-X) \frac{Q_{i}^{j}-Q_{i}^{j-1}}{\Delta t}= \\
=\frac{1}{K}\left[\frac{Q_{i-1}^{j}+Q_{i-1}^{j-1}}{2}-\frac{Q_{i}^{j}+Q_{i}^{j-1}}{2}+\frac{q_{i}^{j}+q_{i}^{j-1}}{2} \cdot \Delta x\right]
\end{gathered}
$$

for $i=2, \ldots, N$ ( $N$ - total number of routing reaches in the channel), from which the unknown values $Q_{i}^{j}$ can be explicitly derived. In order to solve the system, the initial $(t=0 ; j=1)$ and boundary $(x=0 ; i=1)$ conditions must be imposed. In this case, the initial condition is defined by $Q(x)=0\left(Q_{i}^{1}=0\right.$ for $\left.i=1, \ldots, N\right)$. The boundary condition is determined on the basis of the channel inflow hydrograph $Q(x=0, t)$.

In contrast to the classical Muskingum model, in the Muskingum-Cunge version of the method the parameters $K$ and $X$ in Eq. 18 are related to channel characteristics and numerical parameters. The parameter $K$ may be interpreted as the travel time of the flood wave through the channel section (routing reach) and thus may be estimated as (Feldman 2000, Szymkiewicz 2010):

$$
K=\frac{\Delta x}{c},
$$

where $\Delta x$ is the length of the section $\left(\Delta x=x_{j}-x_{j-1}\right)$, and $c$ is the flood wave velocity, which can be calculated on the basis of the channel rating curve:

$$
c=\frac{1}{B} \frac{d Q}{d y}
$$


in which $B$ is the width of the water surface, whereas $Q$ and $y$ are discharge and flow depth, respectively. As an alternative, if the rating curve is not available, flood wave celerity may be estimated on the basis of the average cross-section velocity $v$, as:

$$
c \approx(1.33 \div 1.67) v,
$$

where $v$ is calculated from the Manning equation.

The parameter $X$, after Cunge (1969), may be expressed as:

$$
X=0.5\left(1-\frac{Q_{o}}{B S_{o} c \Delta x}\right),
$$

where $B$ is the top width of a flow area, $S_{o}$ is the bed slope, $c$ is the flood wave speed, $\Delta x$ is the length of the channel reach (equal to the spatial step), and $Q_{o}$ is a reference discharge. The reference discharge can be calculated from the inflow hydrograph as an average value between the base flow and the peak flow (Feldman 2000). As the flow parameters vary in time, the values of $K$ and $X$ must be recalculated for each time step.

In order to ensure accuracy and stability, a special selection of time and distance steps is implemented in HEC-HMS. Details regarding the schemes applied in HEC-HMS are presented by Feldman (2000).

In this study, all channels are drainage conduits of circular cross-sections. Data for the Muskingum-Cunge method (Manning roughness coefficient values, diameters, and bottom slopes) are based on documentation. Base flow in all collectors was established as equal to zero, which is typical of drainage systems during rainless periods.

\subsection{Rainfall Input Data}

In order to evaluate the impact of urbanization on basin runoff under different storm conditions, three variants of rainfall input were assumed in the study:

1. historical hyetograph of the most intensive rainfall event observed in the nearby gauge-station during the period of its operation (since 2009);

2. synthetic hyetograph of the 5-year rainfall event (event with a recurrence time of 5 years), calculated on the basis of the Intensity-Duration-Frequency (IDF) formula for Gdańsk;

3. synthetic hyetograph of the 1-year rainfall event (event with a recurrence time of 1 year), calculated as above.

Owing to the lack of gauge stations in the drainage area under analysis, precipitation data were collected from other stations in Gdańsk. The closest gauge station from which measurement data were available, was a new station established for the needs of a local landfill site. However, the observation period was still too short for any statistical analysis. Therefore, only the most intensive event recorded by this station was used as one of the rainfall scenarios (scenario A). The event was 6 hours long with a total 
precipitation depth of $31.43 \mathrm{~mm}$ (Fig. 9a). The two next scenarios were developed on the basis of long-term observations in other precipitation stations. The IDF-formula for country-regionPoland with parameters specified for Gdańsk was used to calculate the values of rainfall depth corresponding to the assumed values of rainfall duration and recurrence time. In order to determine representative hyetographs of 5-year and 1 -year rainfall events, the synthetic block hyetograph method was applied (Akan and Houghtalen 2003). To estimate the representative rainfall duration, the time of runoff concentration in the basin was determined, and the duration of the synthetic hyetograph was eventually established as $1.5 \cdot t_{c}$. The representative hyetographs obtained for the 5-year and 1-year rainfall events in Gdańsk (scenarios B and C) are presented in Fig. 9b and Fig. 9c, respectively. Scenarios B and C represent a situation typical of Polish conditions, where the maximal rainfall intensity is observed in the first half of rainfall duration. The historical event selected for the analysis (scenario A), however, does not follow this pattern, as two maxima were observed, both in the second half of rainfall duration,.

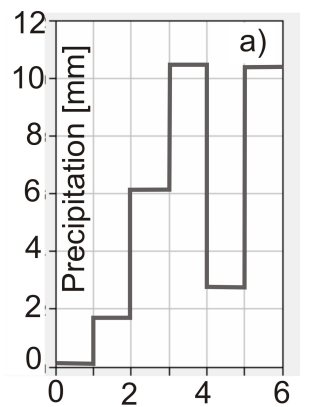

Rainfall duration [hr]

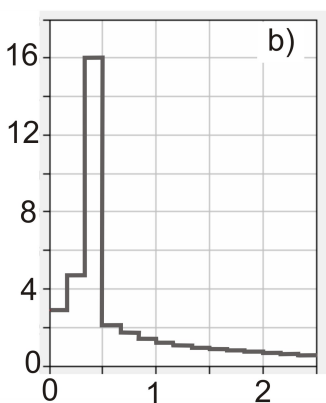

Rainfall duration [hr]

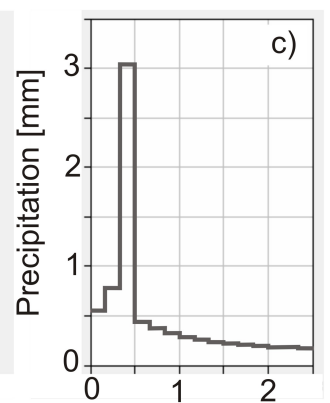

Rainfall duration [hr]

Fig. 9. Rainfall scenarios: a) selected historical event; b) synthetic 5-year hyetograph; c) synthetic 1-year hyetograph (Olechnowicz 2012)

Therefore, despite the fact that the total precipitation depth produced by the event A is close to the corresponding depth of the event B, both scenarios represent totally different situations. Scenario $\mathrm{C}$ is similar to $\mathrm{B}$ as to the intensity distribution in time, but the total precipitation depth is much lower. In all scenarios, rainfall of unlimited range (covering the whole basin) of uniform spatial distribution was assumed.

\section{Results}

In the first stage of calculations, twelve different combinations were considered: four variants of land cover/use (1-4) combined with three precipitation scenarios (A, B, $\mathrm{C})$. The reaction of the basin to different rainfall conditions was analyzed, and the impact of urbanization (under the same rainfall conditions) was compared. Comparison analyses were carried out for each basin component (each sub-basin, conduit, and junction) and for the catchment as a whole (in the outlet cross-section). 
Fig. 10 presents a sample comparison of outlet hydrographs (in outlet cross-section) in 2000 (variant 1) and in 2011 (with one reservoir; variant 2) for two different rainfall scenarios. In 2000, the basin was not much urbanized. Undeveloped areas took up approximately $65 \%$ of the total basin area, whereas dense residential areas took up no more than $10 \%$. No reservoir supported stormwater storage. In this situation, the peak discharge values for scenario A (historical rainfall) and scenario B (5-year rainfall) are $1.720 \mathrm{~m}^{3} / \mathrm{s}$ and $1.816 \mathrm{~m}^{3} / \mathrm{s}$, respectively. Scenario C (synthetic 1-year rainfall) produced no outflow in the outlet cross-section (discharge equal to zero). In 2011, the total rate of undeveloped areas decreased to $38 \%$, and one reservoir (Platynowa) was in operation. In this case, the peak discharge value is much higher in scenario A $\left(3.241 \mathrm{~m}^{3} / \mathrm{s}\right)$ and scenario B $\left(3.885 \mathrm{~m}^{3} / \mathrm{s}\right)$, and remains $0 \mathrm{~m}^{3} / \mathrm{s}$ in scenario C (Fig.10). As can be seen, rainfall $\mathrm{B}$, compared to $\mathrm{A}$, produces higher runoff, occurring earlier and with a longer phase of relatively high discharges, which is a consequence of different shapes of the input hyetographs.

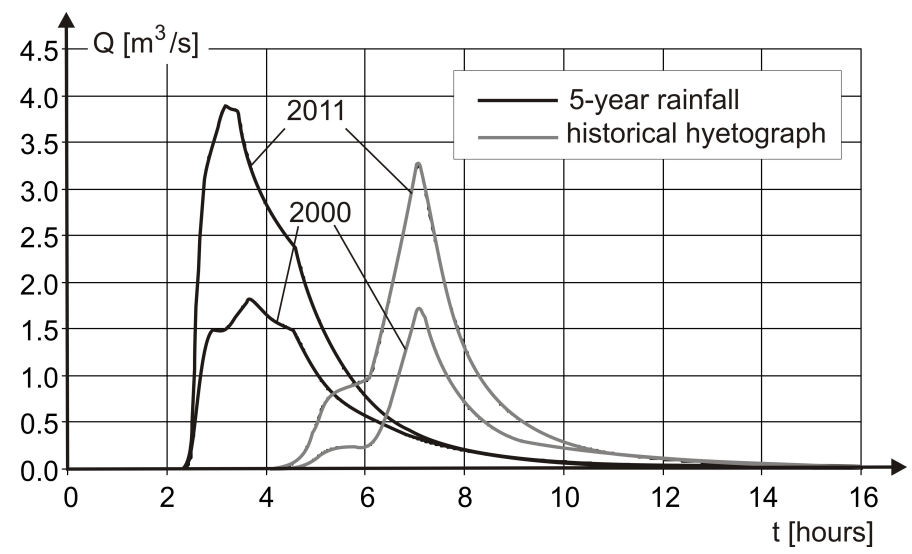

Fig. 10. Outflow hydrographs for 2000 (variant 1) and 2011 (variant 2) for different rainfall scenarios

Fig. 11 presents differences in 5-year runoff hydrographs (in the outlet cross-section) for different variants of urbanization. Table 2 presents a summary of the main results for the selected basin elements for 5-year rainfall. In the case of variant 3 , in which the Madaliñskiego reservoir (r2) was also taken into account, two values of calculation results for sub-basin Z7 (for the upper and lower parts of the basin; Z7.1 and Z7.2, respectively; see 2) are presented.

The results presented in Fig. 10, Fig. 11, and Table 2 indicate considerable influence of urbanization on runoff. This influence manifests itself not only in the intensity of runoff (the value of peak discharge and the total volume of stormwater in runoff), but also in the temporal distribution of runoff (time of peak discharge occurrence and total runoff duration). For all sub-basins, even those in which the least changes due to urbanization are observed (e.g. Z5 and Z6), an increase in runoff is noticeable. For 


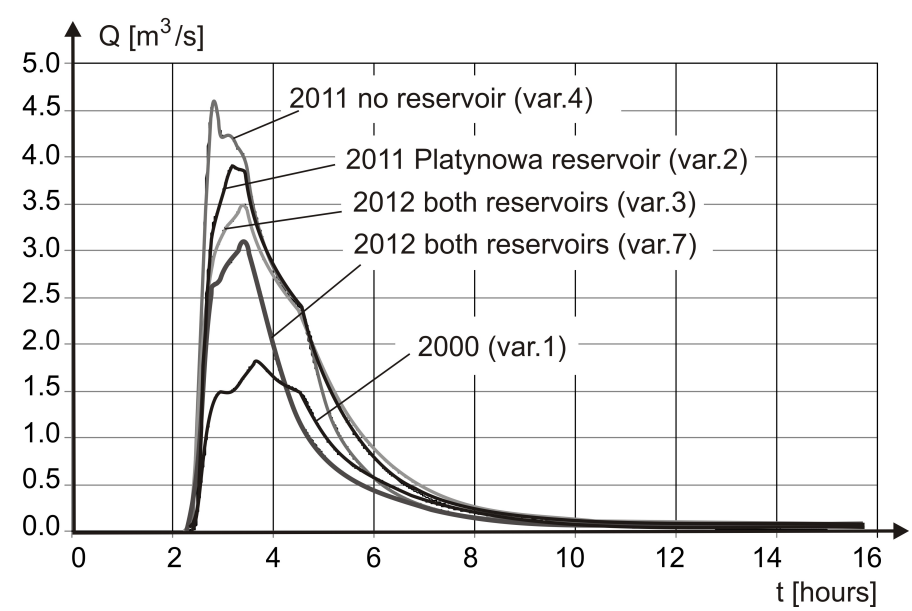

Fig. 11. 5-year outlet hydrographs for different variants of urbanization

sub-basin Z5, the percentage of developed areas (Table 1, categories $\mathrm{C}_{1}, \mathrm{C}_{2}, \mathrm{C}_{5}, \mathrm{C}_{6}$, $\mathrm{C}_{7}$ ) changed from $52 \%$ in 2000 to $60 \%$ in 2011 . In sub-basin $\mathrm{Z6}$, this change is even smaller - the percentage is nearly constant at $61 \%$ in both 2000 and 2011.

Table 2. Summary of the selected results of simulation of 5-year rainfall transformation

\begin{tabular}{|c|c|c|c|c|c|c|c|c|c|c|c|c|}
\hline \multirow{2}{*}{$\begin{array}{c}\text { Hydrologic } \\
\text { element }\end{array}$} & \multicolumn{4}{|c|}{ Peak discharge $Q_{p}\left[\mathrm{~m}^{3} / \mathrm{s}\right]$} & \multicolumn{4}{|c|}{ Time of peak $T_{p}$ [hours] } & \multicolumn{4}{|c|}{ Volume $V\left[1000 \mathrm{~m}^{3}\right]$} \\
\hline & var. 1 & var. 2 & var. 3 & var. 6 & var. 1 & var. 2 & var. 3 & var. 6 & var. 1 & var. 2 & var. 3 & var. 6 \\
\hline $\mathrm{Z1}$ & 0.430 & 0.994 & 0.994 & 0.775 & $2.49^{\prime}$ & 02.44' & 02.44' & 02.46' & 2.5 & 4.0 & 4.0 & 2.8 \\
\hline $\mathrm{Z} 2$ & 0.107 & 0.638 & 0.638 & 0.508 & $3.28^{\prime}$ & 02.38' & 02.38 & 02.39' & 0.8 & 2.0 & 2.0 & 1.3 \\
\hline$\overline{\mathrm{Z} 3}$ & 0.133 & 0.459 & 0.459 & 0.454 & $2.44^{\prime}$ & $02.40^{\prime}$ & 02.40' & 02.40' & 0.9 & 1.7 & 1.7 & 1.3 \\
\hline Z4 & 0.092 & 0.191 & 0.191 & 0.138 & 03.38' & 02.46' & 02.46' & 02.48' & 0.8 & 1.2 & 1.2 & 0.8 \\
\hline $\mathrm{Z5}$ & 0.412 & 0.520 & 0.520 & 0.432 & $02.45^{\prime}$ & $02.45^{\prime}$ & 02.45 & $02.45^{\prime}$ & 2.2 & 2.5 & 2.5 & 1.7 \\
\hline Z6 & 122 & 190 & 0.076 & 190 & $2.35^{\prime}$ & $02.33^{\prime}$ & $02.34^{\prime}$ & $02.33^{\prime}$ & 0.3 & $\overline{0.4}$ & 0.2 & 0.4 \\
\hline Z7 & 0245 & 237 & 0.748 & 1215 & $0436^{\prime}$ & $03.04^{\prime}$ & $02.57^{\prime}$ & 03.02' & 4.0 & 8.7 & 4.8 & 68 \\
\hline & & & 0.585 & & & & \begin{tabular}{|l}
$02.56^{\prime}$ \\
\end{tabular} & & & & 3.6 & \\
\hline $\mathrm{Z8}$ & 0.813 & 1.820 & 1.820 & 1.520 & 03.39' & 03.24' & 03.24' & (03.27' & 8.5 & 14.0 & 14.0 & 10.0 \\
\hline$r l$ & - & 0.479 & 0.479 & 0.415 & - & 03.52' & |03.52' & 03.44' & - & 6.0 & 6.0 & 4.1 \\
\hline$r 2$ & - & - & 0.308 & - & - & - & $04.36^{\prime}$ & - & - & - & 4.8 & - \\
\hline 1.1 & 0.610 & 0.669 & 0.669 & 0.605 & $02.51^{\prime}$ & $02.44^{\prime}$ & $02.44^{\prime}$ & $02.44^{\prime}$ & 4.2 & 7.6 & 7.6 & 5.4 \\
\hline 1.2 & 0.742 & 2.017 & 1.519 & 1.898 & 02.55 & 03.06' & 02.59' & 03.04' & 8.9 & 17.5 & 17.2 & 13.0 \\
\hline 1.3 & 1.786 & 3.836 & 3.483 & 3.319 & 03.41' & 03.12' & $03.25^{\prime}$ & 03.09' & 19.6 & 34.1 & 33.7 & 24.8 \\
\hline J1 & 0.611 & 0.672 & 0.672 & 0.606 & \begin{tabular}{|l}
$02.49^{\prime}$ \\
\end{tabular} & 02.42' & 02.42' & 02.42' & 4.2 & 7.6 & 7.6 & 5.4 \\
\hline $\mathrm{J} 2$ & 0.742 & 2.019 & 1.520 & 1.900 & \begin{tabular}{|l|}
02.52 \\
\end{tabular} & 03.04' & $02.56^{\prime}$ & |03.02' & 8.9 & 17.5 & 17.2 & 13.0 \\
\hline $\mathrm{J} 3$ & 1.787 & 3.837 & 3.484 & 3.320 & 03.39' & 03.10' & 03.23' & $03.07^{\prime}$ & 19.6 & 34.1 & 33.7 & 24.8 \\
\hline Outlet & 1.818 & 3.885 & 3.500 & 3.369 & $03.41^{\prime}$ & 03.11' & $03.25^{\prime}$ & 03.09' & 19.9 & 34.5 & 33.9 & 25.1 \\
\hline
\end{tabular}

However, in both sub-basins an increase in peak discharge is observed - about $30 \%$ for $\mathrm{Z5}$ and as much as $50 \%$ for Z6 (for variant 2). The ratio of the total volume of runoff in 2011 (variant 2) to the corresponding value in 2000 is 1.1 for Z5 and 1.3 for Z6. The cause of this increase is the change in the type of land use/cover 
(e.g. the character of residential areas in the case of Z6), which influences overland friction and the infiltration capacity of the basin. For the most developed sub-basins $-\mathrm{Z} 2$ and $\mathrm{Z7}$ - the influence of urbanization is even more significant. In sub-basin $\mathrm{Z} 2$, the proportional rate of developed areas increased from $10 \%$ to $71 \%$, causing a 6-fold increase in peak discharge and a 2.5 -fold increase in the runoff volume. For Z7, where developed areas took up 11\% in 2000 and 51\% in 2011, a 5-fold increase in peak discharge and a 2.2-fold increase in the total runoff volume were obtained (Table 2).

The time of peak discharge occurrence is also radically different in sub-basins $\mathrm{Z} 2$ and $\mathrm{Z7}$ (it occurs about 1 hour earlier in the developed basin), whereas in less urbanized basins (Z5 and Z6) the effect of development is negligible. For other variants (variant 3 and especially hypothetical variant 4 ) the impact of urbanization is also considerable (Fig. 11). For example, in variant 3 , the calculated values of peak discharge are $2.658 \mathrm{~m}^{3} / \mathrm{s}$ (scenario A) and $3.500 \mathrm{~m}^{3} / \mathrm{s}$ (scenario B). In variant 4 , the corresponding values are $3.658 \mathrm{~m}^{3} / \mathrm{s}$ and $4.587 \mathrm{~m}^{3} / \mathrm{s}$. Therefore, significant impact of urbanization on runoff in the case under analysis was confirmed.

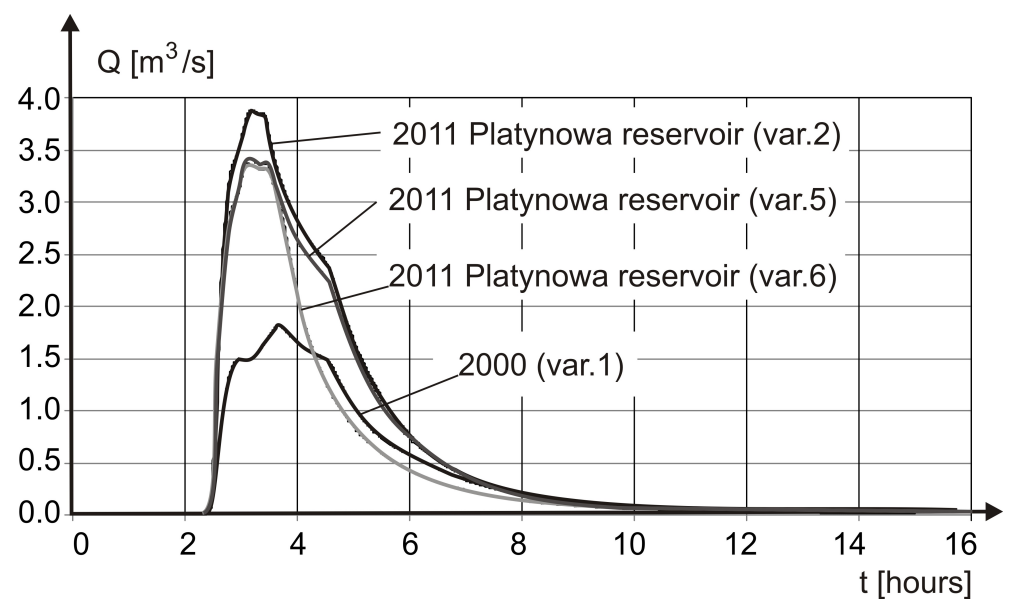

Fig. 12. 5-year outlet hydrographs for alternative variants of urbanization

In the second stage of calculations, alternative variants of land use/cover were analyzed (variants 5-7). The aim of this part of calculations was to verify whether relatively simple strategies of alternative stormwater management can reduce the unfavorable impact of urbanization in the area. Fig. 12 presents the 5-year runoff outlet hydrographs obtained for variants 5-7. One can see the influence of green roofs and permeable pavements on peak discharge and the shape of the hydrograph. Green roofs replacing traditional roofs on commercial centers (variant 5) caused an approximately $22 \%$ reduction in peak discharge (in comparison to variant 2) in $\mathrm{Z1}$, a $17 \%$ reduction in Z5 and a $16 \%$ reduction in Z8 (Table 2), whereas in the total basin (outlet) this reduction amounted to about $12 \%$ (Fig. 12). Permeable pavements (only $2 \%$ of the 
total basin area; variant 6), without causing a significant additional reduction in peak discharge (14\% in comparison to variant 2), did influence the shape of the hydrograph and reduced the total volume of runoff (Fig. 12, Table 2). The presence of reservoirs significantly changes runoff, and this influence is the greater, the larger the flood control storage volume is. A hypothetical $[25 \mathrm{~cm}]$ decrease in the normal storage level in reservoirs (variant 7) resulted in an additional ca 14\% decrease in peak discharge (Fig. 11). This shows the range of possibilities offered by rational stormwater collection and management.

\section{Conclusions and Final Rremarks}

The present study confirmed the important impact of urban development on runoff conditions, its amount, temporal distribution, and intensity. Development of residential and commercial areas, causing a decrease in the proportion of green and undeveloped areas, obviously increases not only the total amount of stormwater in the drainage system, but also the peak value of discharge and the speed of transformation processes. The time of runoff concentration in the basin becomes much shorter, and so does the duration of the flood wave and the lag time. However, these effects can be successfully mitigated by different engineering solutions for alternative stormwater management. One of the most effective, though relatively expensive, is the construction of stormwater reservoirs. In this study, two relatively small reservoirs decreased the peak value in a considerable way. If the water elevation in reservoirs is analyzed and carefully adjusted, additional storage reserves may be found. The study showed a relatively high sensitivity of the amount of drained stormwater to the water elevation in the reservoirs: an additional 14\% decrease in peak discharge was observed after a relatively small decrease in the normal storage level in the reservoirs $(25 \mathrm{~cm})$. What is more, other engineering solutions, although seemingly insignificant, can have considerable influence on the total result. A $22 \%$ decrease in the peak value was observed for green roofs on commercial centers. For green roofs and permeable parking lots together, an even greater runoff volume reduction was observed. One may expect that the impact on the amount of runoff would be still more significant if green roofs were also constructed in at least a part of residential districts.

The study presented the relationship between the level of urbanization and runoff conditions for a small urban basin in Gdańsk (Poland). However, this basin was only a part of a larger, complicated system for stormwater collection and drainage in the city. A complete assessment of drainage system efficiency - measured by the number and frequency of floods in the city, economic and non-economic damage, the comfort of citizens, etc. should be based on system conveyance in a great number of small sub-basins in many districts of the city. The effectiveness of "in source" control by smaller facilities in the upper parts of the city is extremely important for the lower districts (downstream control) and all stormwater recipients, as well. If the influence of relatively simple engineering solutions is so considerable (as shown in the study), 
measures should be taken to increase their application in standard engineering practice for stormwater system design and exploitation.

The calculations presented in the paper have not been validated because of the lack of any discharge/stage measurements in the basin. However, since the methods selected are based on physical interpretation, the parameters of the models can be explicitly defined on the basis of field measurements, maps, and existing documentation. Model calibration and validation would certainly improve simulation results in terms of their consistency with real observations. However, the main aim of the study was to present the general influence of urbanization on runoff, which can be analyzed not only for authentic basins, but also for hypothetical ones. An example of an existing basin, whose characteristics (estimated on the basis of maps and other documentation) change with progressive urbanization, serves as a useful illustration of the problem, as well as shows the main tendencies and leads to important conclusions.

\section{References}

Akan A. O., Houghtalen R. J. (2003) Urban hydrology, hydraulics and stormwater quality. Engineering applications and computer modeling, John Wiley and Sons, Inc., New Jersey.

Campana N. A., Tucci C. E. M. (2001) Predicting floods from urban development scenarios: case study of the Diluvo Basin, Porto Alegre, Brazil, Urban Water, 3, 113-124.

Chaundhry H. C. (1993) Open-channel hydraulics, Prentice Hall, New Jersey.

Chow V. T. (1964) Handbook of Applied Hydrology, McGraw Hill Book Company, New York.

Cunge J. A. (1969) On the subject of a flood propagation computational method (Muskingum method), J. Hydr. Res, 7 (2), 205-229.

Eagleson P. S. (1970) Dynamic hydrology, McGraw-Hill, New York.

Feldman A. D. (ed.) (2000) Hydrologic Modeling System HEC-HMS. Technical Reference Manual, U.S. Army Corps of Engineers, Hydrologic Engineering Center. (http://www.hec.usace. army.mil/software/hec-hms/ 10 August 2014).

Leclerc G., Schaake J. C. (1973), Methodology for assessing the potential impact of urban development on urban runoff and the relative efficiency of runoff control alternatives, Ralph M. Parsons Lab. Report 167. Massachusetts Institute of Technology, Cambridge, Massachusetts.

Lutgens F. K., Tarbuck E. J. (2004) The Atmosphere. An Introduction to Meteorology, Pearson Education Inc., New Jersey.

Mays L. W. (2005) Water Resources Engineering, John Wiley and Sons, Inc., New Jersey.

McCuen R. H. (2005) Hydrological Analysis and Design, Prentice Hall, Englewood Cliffs, New Jersey.

Olechnowicz B. (2012) Alternative management of stormwater for the catchment of the Matomiejska collector in Gdańsk, MSc thesis (manuscript), Gdańsk University of Technology, Gdańsk (in Polish).

Sangjun I., Hyeonjun K., Chulgyum K., Cheolhee J. (2009) Assessing the impacts of land use changes on watershed hydrology using MIKE SHE, Environ. Geol., 57, 231-239.

Scharffenberg W. A. (2013) Hydrologic Modeling System HEC-HMS. User's Manual, ver. 4.0. U.S. Army Corps of Engineers, Hydrologic Engineering Center. (http://www.hec.usace. army.mil/software/hec-hms/documentation.aspx; 08 Sept. 2014).

Shi P-J., Yuan Y., Zheng J., Wang J-A., Ge Y., Qiu G-Y. (2007) The effect of land use/cover change on surface runoff in Shenzhen region, China, Catena, 69, 31-35. 
Soil Conservation Service (1986) Urban Hydrology for Small Watersheds, Technical Report 55. USDA, Springfield, VA.

Szymkiewicz R. (2010) Numerical Modeling in Open Channel Hydraulics, Water Science and Technology Library, Singh V. P. (ed.), Vol. 83. Springer, UK.

Vicars-Groening J., Williams H. F. L. (2007) Impact of urbanization on storm response of White Rock Creek, Dallas, TX, Environ. Geol., 51, 1263-1269.

Walesh S. G. (1989) Urban surface water management, John Wiley \& Sons, Inc., New York.

Wissmar R. C., Timm R. K., Logsdon M. G. (2004) Effects of Changing Forest and Impervious Land Covers on Discharge Characteristics of Watersheds, Env. Management, 34 (1), 91-98.

Wołoszyn E. (2003) The catastrophic flood in Gdansk on July 2001, [In:] Arsov R. et al (eds.) Urban Water Management, Kluwer Academic Publishers,Netherlands, 115-124. 